\title{
Review Paper:Associating Factors With Public Preparedness Behavior Against Earthquake: A Review of Iranian Research Literature
}

\author{
Maryam Ranjbar $^{1,2}$, Ali Akbar Soleimani ${ }^{2,3}$, Bahram Saleh Sedghpour ${ }^{4 *}$, Farahnaz Mohammadi Shahboulaghi ${ }^{1,5}$, Douglas Paton ${ }^{6}$, Mehdi Noroozi ${ }^{1}$
}

1. Social Determinants of Health Research Center, University of Social Welfare and Rehabilitation Sciences, Tehran, Iran

2. Institute for Humanities and Social Studies, Tehran, Iran.

3. Department of Psychology, University of Science and Culture, Tehran, Iran.

4. Department of Educational Psychology, School of Humanities, Shahid Rajaee Teacher Training University, Tehran, Iran.

5. Department of Nursing, University of Social Welfare and Rehabilitation Sciences, Tehran, Iran.

6. Department of Psychology, School of Psychological and Clinical Sciences, Charles Darwin University, Darwin, Northern Territory, Australia.

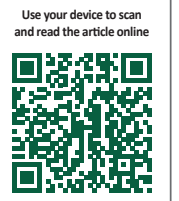

Chtat On: Ranjbar M, Soleimani AA, Sedghpour BS, Mohammadi Shahboulaghi F, Paton D, Noroozi M. Associating Factors With Public Preparedness Behavior Against Earthquake: A Review of Iranian Research Literature. Health in Emergencies and Disasters Quarterly. 2018; 3(2):67-76. https://doi.org/10.29252/NRIP.HDQ.3.2.67

https://doi.org/10.29252/NRIP.HDQ.3.2.67

Article info:

Received: 08 Jun. 2017

Accepted: 15 Oct. 2017

\section{Keywords:}

Earthquake, Preparedness, Public awareness, Community collaboration, Iran

\section{ABSTRACT}

Local preparedness against earthquakes has been recently highlighted in research and policies on disaster management and risk reduction promotion in Iran. To advance the understanding of public preparedness and how it can be applied in diverse localities, further information is required about the predictors of people's adoption of mitigation activities and earthquake preparedness. A synthesis of the available published research results on earthquake preparedness and the influencing factors in Iran are presented in this literature review. It emphasizes the complexity of both the concept of preparedness and the contextual factors that mediate its adoption. The predominant roles of public awareness, trusted information resources, social capital and community collaboration as predictors are discussed.

\section{Introduction}

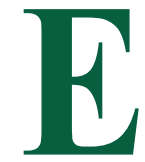

arthquakes, one of the most catastrophic natural events, is characterized by uncertainty in time and place; in other words, these events typically occur without any warning [1]. This unpredictability increases the risk of death and damage, creates mental and physical injuries in most of the affected populations, and is considered a significant threat to the public health [2]. Iran is a highly seismic-prone area because it is located on the Alpines-Himalaya belt and has many active faults. In the past century, the country sustained severe losses in lives, properties, and resources due to the occurrence of more than 40 medium- to large-scale earthquakes that affected the daily living and health of the population for a long time afterwards [3, 4]. The earthquake-related human losses accounted for more than 150.000 deaths in Iran, which is 45 percent of all natural disaster casualties in the country [5]. this accounts for 6 percent of the whole mortality rate aftermath earthquakes while Iranian population is only 1 percent of the total population in the world [3]. A summary of major earthquake consequences in the past two decades in Iran is presented in Table 1.

\section{* Corresponding Author:}

Bahram Saleh Sedghpour, PhD

Address: Department of Educational Psychology, School of Humanities, Shahid Rajaee Teacher Training University, Tehran, Iran.

E-mail: sedghpour@srttu.edu 
There are 3 to 4 times more chances of death and up to 40 times of more injuries related to natural disasters in the developing countries compared to the developed countries [6]. This can result from the significant diversity in the available resources, information and services for people due to their different socioeconomic classes and community situations, which tend to result in different levels of knowledge, awareness, attitude and the ability to predict, prevent and evaluate the consequences of a hazard among them. In developed countries, the victims' behaviors and authorities' decisions are considered important for critical outcomes of a disaster. In contrast, in developing countries, the crises arises mainly due to the lack of information and irrational/ traditional knowledge that can be prevented only through managing and supervising the environment. Therefore, this shows that the communities define their own capabilities and vulnerabilities and have the option to decide which risks are important [7]

The consequences of earthquakes depend on its magnitude, the focal distance from the urban area, the preparedness level, and the mitigation measures in the nearby residence [2]. Preparedness represents the essential steps that could raise the probability of avoidance or minimize the calamitous consequences of a hazard, which is considered as a basic component in any disaster risk reduction. These kinds of efforts have a predominant focus on human behaviors deriving from different factors [8].

Recently, international approaches to risk management have focused on the integrated process of pre-disaster risk reduction (prevention, mitigation and preparedness behaviors) followed by planning for post disaster actions for enhancing the resilience in the community to proactively decrease the impacts of the disaster. This has become a national strategy and the basis of reducing hazard risk in developed countries [9]. But studies suggested that despite the serious threat of seismic events, the levels of adoption of preparedness measures in developed and developing countries is low. This increases the magnitude of (preventable) losses that have occurred [4].

Despite the effort and considerable expenditure on public education, the level of individual and community earthquake preparedness among people living in highly vulnerable regions of Iran is low [4, 7, 10-13]. Furthermore, there is little evidence of people learning lessons from the destructive earthquakes that have occurred in recent decades $[14,15]$. There is a discrepancy between risk knowledge and perception and preparedness behaviors in people living in Iran $[4,10,11,16]$. In addition to issues concerning risk acceptance, factors such as social class, gender and/or other special conditions act to influence preparedness behavior [17]. Taken together, these factors identify a need to define which factors influence the people's preparation decisions regarding hazards such as earthquakes.

A review of research literature can provide meaningful information on identifying the gaps that need to be filled and articulate the opportunities that exist for enhancing the rates of preparedness at all levels of society. Considering the lack of any previous review of Iranian research literature on earthquake preparedness behavior, the present study was conducted to rectify this and identify the factors associated with earthquake preparedness in Iranian people.

\section{Materials and Methods}

This review was conducted to describe and analyze Iranian research literature regarding the factors associated

Table 1. The casualties, injuries and economic damages of major earthquakes (magnitude $\geq 6$ Richter) in Iran since 1990

\begin{tabular}{|c|c|c|c|c|c|}
\hline \multirow{2}{*}{ Earthquake } & \multirow{2}{*}{ Magnitude } & \multirow{2}{*}{ Year } & \multicolumn{2}{|c|}{ Human Losses } & \multirow{2}{*}{ Direct Economic Losses (Million \$) } \\
\hline & & & Mortalities & Injuries & \\
\hline Manjil-Roudbar & 7.1 & 1900 & $40,000^{*}$ & $710,000 *$ & 3505 \\
\hline Bojnord & 6.1 & $1997^{*}$ & $100 *$ & $84,500 *$ & 99 \\
\hline Ghaen-Birjand & 7.3 & 1997 & 1,567 & $74,600 *$ & 280 \\
\hline Changureh (Avaj) & 6.2 & 2002 & 230 & 1,466 & 65 \\
\hline Bam & 6.5 & 2003 & $26,796^{*}$ & $267,628^{*}$ & 2995 \\
\hline Azarbaijan & 6.4 & 2012 & $306 *$ & $61,546^{*}$ & 894 \\
\hline Kermanshah & 7.3 & 2017 & $620 * *$ & $7156 * * *$ & Not reported yet \\
\hline
\end{tabular}

** Kermanshah General Office of Legal Medicine website [accessed: 2017 December 19]

*** Rechecked with Emergency Medical Services Organization in 2017/22/11 
Table 2. Search strategy and key words used to search each database

\begin{tabular}{|c|c|c|c|c|c|}
\hline $\begin{array}{l}\text { Data } \\
\text { Base }\end{array}$ & Keywords & $\begin{array}{l}\text { Articles } \\
\text { Found }\end{array}$ & $\begin{array}{l}\text { Research } \\
\text { Conducted } \\
\text { in Iran }\end{array}$ & Selected & Date \\
\hline PubMed & $\begin{array}{c}\text { ((((((Earthquake [Title/Abstract]) OR seismic [Title/Abstract]) OR natural } \\
\text { disaster [Title/Abstract]) OR natural hazard [Title/Abstract])) AND } \\
\text { (((prepar* [Title/Abstract]) OR readiness [Title/Abstract]) OR mitigat* } \\
\text { [Title/Abstract])))) OR earthquake preparedness [Title/Abstract]) OR } \\
\text { preparedness behavior [Title/Abstract] AND (Humans [Mesh] AND } \\
\text { English [lang])) }\end{array}$ & 451 & 17 & 3 & 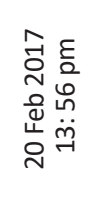 \\
\hline Scopus & $\begin{array}{c}\text { (TITLE-ABS-KEY (factors) AND TITLE-ABS-KEY (preparedness OR readi- } \\
\text { ness OR “mitigation behavior" OR "preventive behavior" OR "adaptive } \\
\text { behavior") AND TITLE-ABS-KEY ("earthquake" OR seismic OR “natural } \\
\text { disaster" OR "natural hazard") ) AND (EXCLUDE (SUBJAREA, "SOCI OR } \\
\text { ENVIOR PSYC OR HEAL OR MULT AND LIMIT-TO LANGUAGE") ) AND } \\
\text { (LIMIT-TO ( SUBJAREA, "SOCI") OR LIMIT-TO (SUBJAREA, "PSYC") OR } \\
\text { LIMIT-TO (SUBJAREA, "HEAL") OR LIMIT-TO (SUBJAREA, “DECI") OR } \\
\text { LIMIT-TO (SUBJAREA, "MULT")) }\end{array}$ & 186 & 4 & - & 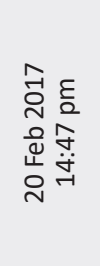 \\
\hline $\begin{array}{l}\text { Web of } \\
\text { Science }\end{array}$ & $\begin{array}{c}\text { TOPIC: ((prepar* OR read* OR “preparedness behavior” OR “mitigation } \\
\text { behavior” OR “preventive behavior” OR “adaptive behavior”)) AND } \\
\text { TOPIC: ((“earthquake” OR seism* OR “natural disaster” OR “natural } \\
\text { hazard”)) } \\
\text { Refined by: WEB OF SCIENCE CATEGORIES: (EMERGENCY MEDICINE OR } \\
\text { PSYCHOLOGY MULTIDISCIPLINARY OR PSYCHOLOGY SOCIAL OR MUL- } \\
\text { TIDISCIPLINARY SCIENCES OR SOCIAL SCIENCES INTERDISCIPLINARY } \\
\text { OR PSYCHOLOGY OR SOCIOLOGY OR SOCIAL ISSUES ) AND RESEARCH } \\
\text { AREAS: (PSYCHOLOGY OR EMERGENCY MEDICINE OR SOCIAL SCIENCES } \\
\text { OTHER TOPICS OR SOCIOLOGY OR SOCIAL ISSUES) AND LANGUAGES: } \\
\text { (ENGLISH) } \\
\text { Timespan: All years; Indexes: SCI-EXPANDED, SSCI, CPCI-S, CPCI-SSH, } \\
\text { ESCI }\end{array}$ & 156 & 6 & $1^{*}$ & 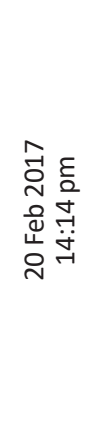 \\
\hline SafetyLit & $\begin{array}{c}\text { (Preparedness OR readiness OR mitigation OR preparedness behavior } \\
\text { OR disaster preparedness OR earthquake preparedness) AND (earth- } \\
\text { quake OR seismic OR natural hazard OR natural disaster) }\end{array}$ & 1198 & $16+16^{*}$ & 4 & 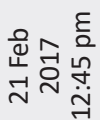 \\
\hline SAGE & $\begin{array}{c}\text { Ti: (preparedness OR readiness OR mitigation) AND (earthquake OR } \\
\text { seismic OR hazard) }\end{array}$ & 8 & 0 & 0 & 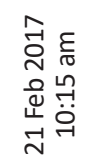 \\
\hline $\begin{array}{l}\text { Wiley } \\
\text { Online } \\
\text { Liberary }\end{array}$ & $\begin{array}{c}\text { Earthquake preparedness in article titles OR preparedness behavior in } \\
\text { article titles OR preparedness in article titles OR mitigation in article } \\
\text { titles OR mitigation behavior in article titles AND earthquake in article } \\
\text { titles OR seismic in article titles OR natural disaster in article titles OR } \\
\text { natural hazard in article titles }\end{array}$ & 8475 & $19+1^{*}$ & $1^{*}$ & 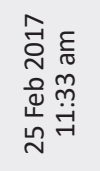 \\
\hline SID & $\begin{array}{c}\text { Preparedness behavior OR mitigation OR prevent* (Key words) AND } \\
\text { earthquake (Topic) "in Persian language" }\end{array}$ & 16 & $13+3^{*}$ & 2 & 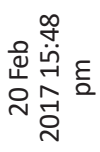 \\
\hline Magiran & $\begin{array}{c}\text { Preparedness behavior OR mitigation OR prevent* (Key words) AND } \\
\text { earthquake (Topic) "in Persian language" }\end{array}$ & 34 & $23+11^{*}$ & 3 & 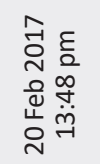 \\
\hline & Total & 10.524 & 129 & 12 & \\
\hline
\end{tabular}

* Used to show the number of articles that were found in at least one other prior database 
with earthquake preparedness. We found no prior literature review related to this topic via the Cochrane Library.

\section{Search strategy}

Key words and MeSH terms were used to search in eight medical, psychological, public health and social sciences electronic databases in both English and Persian languages. The databases, key words and terms are summarized in Table 2. We also searched the related references of the selected articles in Google Scholar and found 3 other relevant full papers, which were included in the 15 articles selected at the end of our search. Searching of databases ended on $25^{\text {th }}$ February 2017.

\section{Inclusion criteria}

We included all the documents that presented the factors associated with public earthquake preparedness behavior all around Iran. Original articles, clinical trials, case presentation/studies, review articles and available electronic books and book chapters were reviewed. The outcome incorporated in this review was public earthquake preparedness behavior; accordingly, we defined it as the public behaviors which could meet two major goals: preparing the necessary supplements or an emergency kit and having a mitigation plan for the family and/or the neighborhood. All the included studies were reported in English or Persian languages. This review started on $19^{\text {th }}$ February 2017 and finished on $15^{\text {th }}$ August 2017 and had no time limitations for the publication dates.

\section{Review protocol}

All the retrieved titles and abstracts were screened to identify and remove duplicates and ineligible studies. This selection and full text articles were double screened and agreement measured. All the study team approved the selection.

We then identified the candidate documents through the following screening process. Firstly, all the found documents $(\mathrm{N}=10524)$ were refined by examining the relevance of their titles relevance. This resulted in 129 articles (99+31 duplications) related to the Iranian population. We then applied the inclusion criteria to the abstracts and finally selected 15 full-text articles for inclusion in this review study. All of the selected articles were related to earthquake preparedness and its associating factors in the Iranian people (Figure 1).

We included both original research designs (qualitative/quantitative) in this review in order to obtain the

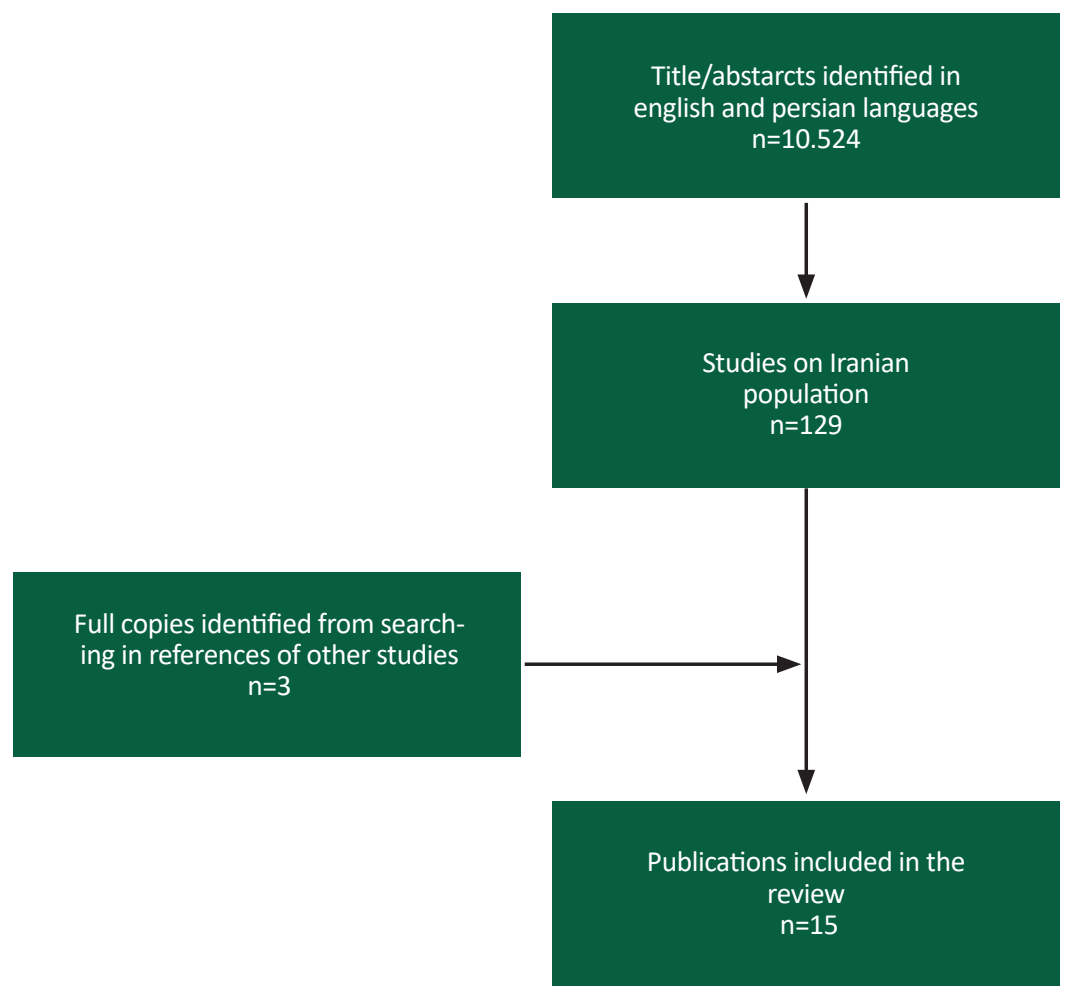

Figure 1. The protocol of article review 
Table 3. Key findings of the studies about public earthquake preparedness

\begin{tabular}{|c|c|c|c|c|}
\hline Author & Year & Design & Population/N/Sampling & Key Findings \\
\hline $\begin{array}{l}\text { Ardalan et } \\
\text { al. [18] }\end{array}$ & 2013 & $\begin{array}{l}\text { Interventional (Controlled } \\
\text { trial with pre-post assess- } \\
\text { ment) }\end{array}$ & $\begin{array}{l}9200 \text { households in interven- } \\
\text { tion and } 10010 \text { households in } \\
\text { control areas of } 3 \text { provinces in } \\
\text { Iran/1500 ( } 250 \text { each area each } \\
\text { province)/Systematic random } \\
\text { sampling of registered house- } \\
\text { holds in each area }\end{array}$ & $\begin{array}{l}\text { There was a significant correlation between community } \\
\text { risk perception and previous experiences of natural } \\
\text { disasters with relative changes in awareness and readi- } \\
\text { ness. The combination of group training, face to face } \\
\text { education, and color posters was significantly corre- } \\
\text { lated with the higher levels of awareness and readiness } \\
\text { among the intervention participants. }\end{array}$ \\
\hline $\begin{array}{l}\text { Taghizadeh } \\
\text { et al. [19] }\end{array}$ & 2012 & $\begin{array}{l}\text { Observational (cross-sec- } \\
\text { tional) }\end{array}$ & $\begin{array}{l}\text { Tehran residents } \geq 15 y r s / 1195 / \\
\text { systematic random sampling } \\
\text { in randomly chosen blocks of } \\
\text { all } 22 \text { districts of Tehran }\end{array}$ & $\begin{array}{l}\text { Low knowledge, high-school education or less and liv- } \\
\text { ing in Northern high-risk regions of Tehran were related } \\
\text { to lower levels of preparedness against earthquake. } \\
\text { Having no previous experience about earthquakes } \\
\text { and job status were identified as risk factors to low } \\
\text { preparedness. Living in the Southern high-risk regions } \\
\text { were significantly related to higher levels of knowledge } \\
\text { about earthquakes compared to people living in low- } \\
\text { risk regions. }\end{array}$ \\
\hline
\end{tabular}
Jamshidi et 2016 Interventional with control Tehran/305 intervention+314 al. [21] $2016 \quad$ neighborhood control/Systematic cluster sampling

Public education about disaster preparedness affects the knowledge, attitude and preparedness behavior of people, but a collaborative approach is essential to preserve the level of obtained preparation.

The education level of the head of household contributed to the preparedness trainings, whereas age, gender, past experience of earthquakes, marriage situation and the size of household were insignificant factors regarding to their earthquake preparedness.

All the residents of quake prone cities of Fars prov-

$\begin{array}{llrl}\text { Rakhshani } & 2016 & \begin{array}{c}\text { Observational (cross-sec- } \\ \text { et al. [13] }\end{array} & \begin{array}{c}\text { prone cities of Fars prov- } \\ \text { ince/500/Systematic random }\end{array}\end{array}$
cluster sampling
Income level, past experience of disaster, district of residence and job situation had a significant direct effect on disaster preparedness among Tehran citizens. Gender, family members in a household, type of house home ownership and being the head of household had no significant effect on preparedness. Only 10 percent of the participants scored more than the medium 4 disaster preparedness behaviors.

Age, knowledge, home ownership and education leve were related to actual mitigation behaviors. While risk perception showed positive effects, but controllability, trust to the urban emergency authorities and the length of stay had negative direct effects on the intention to mitigate behavior. The indirect effects of age, self-efficacy, need to protection, optimistic biases and income mediated by risk perception on intention to mitigation action had been significant.

\begin{tabular}{|c|c|c|c|}
\hline $\begin{array}{l}\text { Asgarizadeh } \\
\text { et al. [10] }\end{array}$ & 2014 & $\begin{array}{c}\text { Observational (cross-sec- } \\
\text { tional) }\end{array}$ & $\begin{array}{c}\text { Head of households in } \\
\text { Tehran } \geq 18 y r s / 267 / \text { Not } \\
\text { specified }\end{array}$ \\
\hline
\end{tabular}

Hosseini et $2014 \quad$ Case study
4 communities in 3 districts of Tehran/102 for the $1^{\text {st }}$ workshop +10 of former participants for $2^{\text {nd }}$ workshop +125 school children 8-13 yrs +53 school teachers/Purposeful+p urposeful+random+volunteer sampling
The importance of community capabilities (awareness of both vulnerability and mitigation criteria) in decreas ing the impacts of earthquake and the community's effective responses has been highlighted. Communitybased organizations were identified with some physical, informational and technical shortages in disaster mitigation and management.

The practice of preparedness against earthquake showed higher levels related to female participants. Education level and job situation had significant relations with knowledge regarding preparedness. Age had a significant relation with knowledge and showed negative impacts on practice of preparedness. The attitude of preparedness was significantly higher among students. 


\begin{tabular}{|c|c|c|c|c|}
\hline Author & Year & Design & Population/N/Sampling & Key Findings \\
\hline $\begin{array}{l}\text { Ghadiri et } \\
\text { al. [17] }\end{array}$ & 2013 & $\begin{array}{c}\text { Observational (cross-sec- } \\
\text { tional) }\end{array}$ & $\begin{array}{l}300380 \text { households of Shiraz } \\
\text { in 2011/350/Random cluster } \\
\text { sampling }\end{array}$ & $\begin{array}{l}\text { Job position, income, education level and socio-eco- } \\
\text { nomic status had significant effects on the community's } \\
\text { earthquake preparedness in a positive way. }\end{array}$ \\
\hline $\begin{array}{l}\text { Khankeh et } \\
\text { al. [23] }\end{array}$ & 2013 & $\begin{array}{l}\text { Interventional (Controlled } \\
\text { trial with pre-post and } \\
\text { followup- } 40 \text { days after- as- } \\
\text { sessment) }\end{array}$ & $\begin{array}{c}\text { High-school boys in } \\
\text { Eshtehard-Karaj/117: } \\
\text { 53(experiment)+64(control)/ } \\
\text { Inclusion criteria+random } \\
\text { assignment in control-experi- } \\
\text { ment groups }\end{array}$ & $\begin{array}{l}\text { Education of high school children could significantly in- } \\
\text { crease the level of knowledge, anxiousness and skills of } \\
\text { their household preparedness in the experiment group. } \\
\text { Skill of confrontation as an outcome was consistent } \\
\text { with their preparedness behavior }\end{array}$ \\
\hline
\end{tabular}
Nikmard
Namin et
al. [6]
Qualitative: developing
questionnaire+Observationa
(cross-sectional survey)
The households of district 22
in Tehran/96/not specified

The level of contribution in preparedness against earthquake was significantly higher among young female adults who had a higher sense of belonging to the place in which they lived. Education was related to the level of risk knowledge and perception.

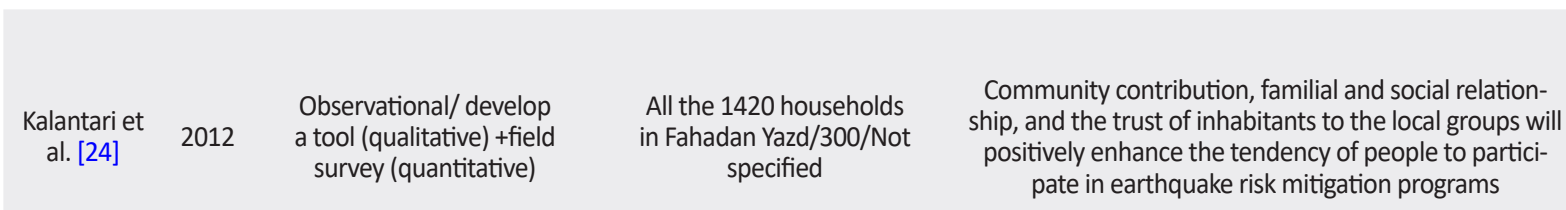

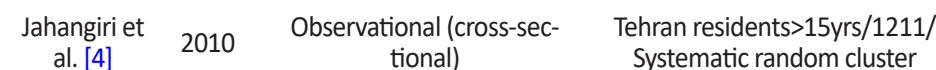

Job position, location of house, old age, not being married, low education level and crowded households had less knowledge, attitude and practice of earthquake preparedness

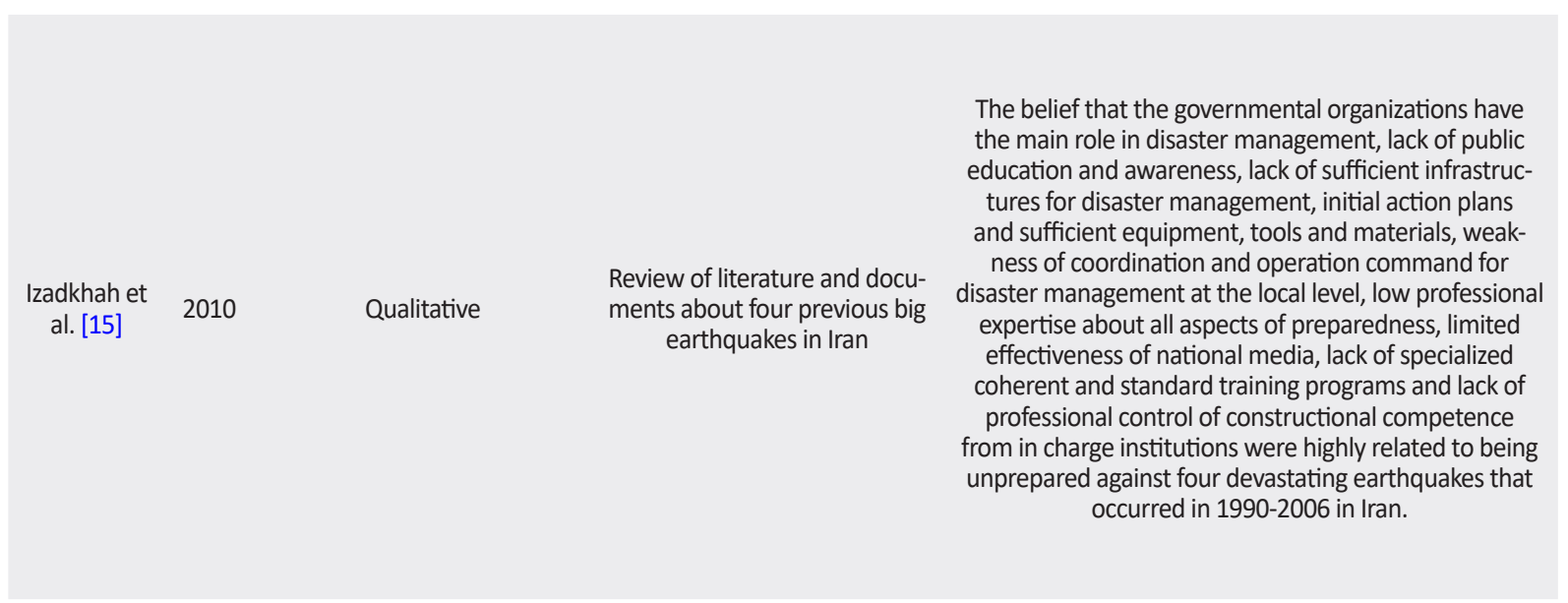

Asgary et

al. [2]
1997
Observational (cross-sectional survey)
Residents of Tehran and Rasht in 1994/1300 Tehran+600

Rasht/Multistage cluster sampling
Fatalistic attitudes and risk perception were significant determinants of households' responses in both cities (Tehran, Rasht). Meanwhile, economic status influenced mitigatory response only in Tehran. The other influencing variables (Intercept, earthquake safety needs and threat) were found to be insignificant with respect to the household mitigation behaviors. 
broadest available evidences. Studies on post-event issues and those responding to disaster and rehabilitation, managerial elements, buildings mitigation engineering and geophysical parameters rather than discussing public preparedness behavior were excluded. In addition, an editorial, a letter to editor, and a brief report were also excluded.

\section{Results}

In total, 15 articles met the inclusion criteria. Tehran citizens were the participants in seven studies published between 1997 and 2016. Households comprised the most common subject groups in all the studies. The majority of the selected studies were quantitative research projects that employed self-made and/or standard questionnaires. The qualitative studies mostly used in-depth interviews and focus group discussions.

The source articles were assessed for reporting validity and reliability. Eight articles reported acceptable ranges of Cronbach's alpha as the reliability measure of the instrument. The evidences of at least one validity measurements of the tools were produced in eight papers. Standardized instruments were used in two source articles. One source was purely qualitative and used content analysis of literature and documents. Validity and reliability measures for the tools used in three surveys and two field work interventional studies were not introduced. Twelve source articles provided sufficient details of their sampling strategies. Systematic Random cluster or multi-stage sampling was the most common sampling methods used in these studies. Purposive or convenient sampling was employed in 2 smaller qualitative studies. A few studies (4 of 15) addressed the issues of missing data and response rate.

\section{Earthquake preparedness}

Preparedness is a multidisciplinary concept that draws expertise from various fields such as economics, information technology, medicine, psychology, social studies, and public health. This diversity means that the definitions and measures of preparedness vary considerably between scientists and researchers in different disciplines. Academicians generally defined the frame of earthquake preparedness as collecting a standard set of supply stockings besides having a plan for mitigation. They have tried to identify both the barriers to earthquake preparedness and its facilitators. Most studies identified insufficient disaster preparedness of communities and households all over the country $[4,7$, $10,11,13,15,20-22]$.
Low knowledge and attitude about earthquake mitigation activities in communities were accompanied with less preparedness practice [4, 19]. However, public awareness regarding earthquake mitigation was commonly reported to be infrequent [4, 15, 18-23]. Five studies noted the positive effect of public education in improving knowledge and practice 15, 18, 21-23] while two others demonstrated that preparedness would not often be improved only by providing related education and information for people [10, 20].

Some results emphasized on the effectiveness of community-based activities on public awareness, attitude and actions of preparedness [7, 21, 22]. Communities rarely collaborated with their local authorities related to mitigation and preparation. There are cultural and fatalistic beliefs/attitudes that could inhibit positive outcome expectancies and impose the doubt of ineffectiveness of mitigation and preparedness against disasters like earthquake [4] while affecting disaster preparedness [15] in the whole country.

\section{Factors influencing public preparedness}

\section{Demographic determinants}

Primarily, demographic characteristics have shown different impacts on earthquake preparedness of Iranian people. Age was mentioned in 7 articles (in one not as a significant factor [13]; in the others, it had direct [4, 6 , $16,22]$ and/or indirect $[10,19]$ effect on preparedness. This work indicated that younger people were inclined to be more aware and prepared [21]. Job position [4, 11, 16, 19], income level and socioeconomic status [7, 10, 11, 20], education $[4,7,10,13,16,18,19,21]$ were identified as having both direct and indirect positive impacts on preparedness knowledge and behavior. Gender [6, 16], marriage status [4], and having previous experience of earthquake [19] were also indicated as having a significant positive influence on increasing awareness and readiness in some studies, whereas other studies reported them to be insignificant $[11,13,19,21]$. Home ownership $[11,19]$ and family size $[11,13]$ were not found to influence public preparedness. However, house location or the region in which people lived $[4,11,18]$ was identified as having a positive impact on preparedness.

\section{Earthquake preparedness awareness}

Some variations in knowledge about general earthquake preparedness in the communities were observed. However, the impact of education on knowledge, attitude and practice revealed different findings. Exposure 
to preparedness information was associated with increasing knowledge, perception of risk, and practice in some studies [18, 21, 23], whereas good knowledge of earthquake risk and high risk perception was not necessarily associated with preparedness behavior in some others $[10,20]$. The higher levels of education and better awareness is related to the behavior of preparedness among the general public $[4,6,7,13,16,19]$, which was also correlated with their prior experiences of such event $[11,13,19]$.

\section{Psychosocial predictors}

Some studies suggested psychosocial factors that can increase knowledge, attitude and behavior of earthquake preparedness in different Iranian communities. The positive direct impacts found for participatory interventions were mediated by empowering local communities and mutual trust [21], risk perception [10], sense of belonging to the place of living [6], community contribution, social and familial relations and general trust [24]. Accordingly, the responsibility belief, optimistic biases, self-efficacy, and the need for protection were mentioned as the predicting factors that showed indirect impacts through increasing risk perception on the seismic preparation activities in the communities [10]. Controllability, trust to emergency authorities [10], technical, informational and physical shortages in community organizations [16] were found to be the factors that could hinder the preparedness action in different societies (Table 3).

The limitations of the current study were as follows: It is possible that we have missed some relevant publications (e.g. research reports that do not have wide circulation) in spite of the systematic search protocol used in this review. Although both English and Persian databases were included, we cannot discount the possibility that some potentially relevant studies may have been omitted due to the used search strategy and inclusion criteria. However, considering these limitations, the present review could identify several articles with pertinent topics and content. The research methods used in these fifteen studies were diverse, but we included all of them to optimize the scope and integration of the literature included in the review. This can give us a more authentic picture of the current research into the actual earthquake preparedness in Iran.

\section{Conclusion}

This review suggested the necessity of providing clear, realistic, operational and trustable preparedness directives for the general public soliciting their own collaboration. The literature is inconclusive about the influenc- ing and hindering factors meanwhile contradictory in some aspects. The topics did not include perceived versus actual preparedness, preferable sources of information, the exact role of government and authorities, and the influencing factors on the preparedness of minorities and special groups. Operationally, the lack of necessary information, fatalistic attitudes and low level of general trust and collaboration in the general public have been mentioned as inhibiting factors. It appears that specific instructions based on community participation besides encouraging the activities that enhance general trust and eliminate mistrust to the authorities and the information resources they provide may have positive impacts on the potential resiliency and actual preparedness against earthquake. Understanding how community members perceive the relevance of preparedness and vulnerability to their own lives needs to be investigated.

\section{Acknowledgments}

This article reports the initiating part of the study collaboration between the Social Determinants of Health Research Center and The Institute of Humanities and Social Studies.

\section{Conflict of Interest}

The authors declared no conflicts of interest.

\section{References}

[1] Rabeian M, Hosseini SH, Radabadi M, Taheri Mirghaed M, Bakhtiari M. [Evaluation of effective factors on the rate of preparedness of Tehran university of medical sciences' selected hospitals in dealing with earthquake (Persian)]. Journal of Payavard Salamat. 2013; 7(3):251-61.

[2] Naghii M. Public health impact and medical consequences of earthquakes. Revista Panamericana de Salud Pública. 2005; 18(3):216-21. PMID:16269124

[3] Zangiabadi A, Khosravi F, Sahraeean Z. [Extracting the Index for identifying the old structures using GIS system: Case study of the western timeworn region of Jahrom city [Persian)]. Human Geography researches. 2011; 43(4):117-36.

[4] Jahangiri K, Azin S, Mohammad K, Rahimi Foroushani A. [Factors Affecting Tehran Residents' Preparedness against Earthquake in 2007 (Persian)]. Hakim. 2010; 13(3):155-65.

[5] Guha-Sapir D, Below R, Hoyois P. EM-DAT: Country profile: Iran. Brussels - Belgium: EM-DAT: The CRED/OFDA International Disaster Database [Internet]. 2016 [Updated 2016 November 17]. Available from: www.emdat.be 
[6] Nikmard Namin, S, Barakpour N, Abdollahi M. [Risk reduction of earthquake with emphasis on social factors of resilience (Case study: District 22 of Tehran) (Persian)]. Urban Management, 2015; 13(37):19-34.

[7] Ghadiri M. [Socio-economic factors in residential vulnerability to earthquake in Tehran city (Persian)]. Geographic Space. 2013; 15(51):241-62.

[8] Ejeta LT, Ardalan A, Paton D. Application of behavioral theories to disaster and emergency health preparedness: a systematic review. PLoS currents. 2015; 7. doi: 10.1371/currents.dis.31a8995ced321301466db400f1357829

[9] Ostadtaghizadeh A, Ardalan A, Paton D, Jabbari H, Khankeh HR. Community disaster resilience: a systematic review on assessment models and tools. PLoS currents. 2015; 7. doi: 10.1371/currents.dis.f224ef8efbdfcf1d508dd0de4d8210ed

[10] Asgarizadeh Z, Rafieian M, Dadashpour H. [The evaluation and analysis of empirical model of earthquake mitigation behaviors in Tehran households (Persian)]. Geography and Environmental Hazards. 2015; 4(15):39-60. doi: 10.22067/geo. v4i3.41900

[11] Najafi M, Ardalan A, Akbarisari A, Noorbala AA, Jabbari H. Demographic determinants of disaster preparedness behaviors amongst Tehran inhabitants, Iran. PLoS currents. 2015; 7. doi: 10.1371/currents.dis.976b0ab9c9d9941cbbae3775 a6c5fbe6

[12] Zarghami S, Teimouri A, Mohammadian H, Shamaee A. [Measuring and evaluating urban neighborhood's resilience against earthquake: The case of Zanjan downtown (Persian)]. Research and Urban Planning. 2017; 7(27):77-92.

[13] Rakhshani T, Abbasi S, Ebrahimi MRa, Taravatmanesh S, Investigating the preparedness status of households against earthquake in Fars Province in 2013; A cross sectional study. Iranian Journal of Emergency Medicine. 2016; 3(2):66-72.

[14] Ibrion M, Mokhtari M, Nadim F. Earthquake Disaster Risk Reduction in Iran: Lessons and "Lessons Learned" from Three Large Earthquake Disasters - Tabas 1978, Rudbar 1990, and Bam 2003. International Journal of Disaster Risk Science. 2015; 6(4):415-27. doi: 10.1007/s13753-015-0074-1

[15] Izadkhah Y, Amini Hosseini KA. An evaluation of disaster preparedness in four major earthquakes in Iran. Journal of Seismology and Earthquake Engineering. 2010; 12(1-2):61.

[16] Mahdaviazad H, Abdolahifar G. Assessing household natural disaster preparedness in Shiraz, Iran, 2011: Results of a knowledge, attitude, and practices survey. Disaster Medicine and Public Health Preparedness. 2014; 8(4):349-52. doi: 10.1017/dmp.2014.61

[17] Ghadiri M, Nesbi N. Analyzing the preparedness differences of neighborhood communities of Shiraz city to earthquake hazard. Spatial Planning (Modares Human Sciences). 2013; 17(2):71-91. doi: 10.22059/jurbangeo.2015.55351

[18] Ardalan A, Mowafi H, Ardakani HM, Abolhasanai F, Zanganeh AM, Safizadeh H, et al. Effectiveness of a primary health care program on urban and rural community disaster preparedness, Islamic Republic of Iran: A community intervention trial. Disaster medicine and public health preparedness. 2013; 7(5):481-90. doi: 10.1017/dmp.2013.93

[19] Taghizadeh AO, Hosseini M, Navidi I, Mahaki AA, Ammari H, Ardalan A. Knowledge, attitude and practice of Teh- ran's inhabitants for an earthquake and related determinants. PLoS currents. 2012; 4. doi: 10.1371/4fbbbe1668eef

[20] Asgary A, Willis KG. Household behaviour in response to earthquake risk: An assessment of alternative theories. Disasters. 1997; 21(4):354-65. doi: 10.1111/1467-7717.00067

[21] Jamshidi E, Majdzadeh R, Namin MS, Ardalan A, Majdzadeh B, Seydali E. Effectiveness of community participation in earthquake preparedness: A community-based participatory intervention study of Tehran. Disaster Medicine and Public Health Preparedness. 2016; 10(2):211-8. doi: 10.1017/ dmp.2015.156

[22] Hosseini KA, Hosseini M, Izadkhah YO, Mansouri B, Shaw T. Main challenges on community-based approaches in earthquake risk reduction: case study of Tehran, Iran. International Journal of Disaster Risk Reduction. 2014; 8:114-24. doi: 10.1016/j.ijdrr.2014.03.001

[23] Amanat N, Khankeh H, Hosseini MA, Mohammadi F, Aghighi A, Sadeghi A. The effect of earthquake preparedness training to male high school students on families. Journal of Rescue \& Relief. 2013; 5(3):27-39.

[24] Kalantari Khalilabad H, Mahdavieh SM, Fallah Ali Abadi $\mathrm{S}$. [The study on the role of social capitals for reducing the risk of earthquake in historic textures in Yazd (Case study: Fahadan neighborhood) (Persian)]. Journal of Studies On Iranian - Islamic City. 2012; 3(9):5-14. 
